\title{
Research on Dynamic Game Model of Enterprise Green Technology Innovation Driving Force
}

\author{
Zhong Liu*, Zheng Jianguo \\ Glorious Sun School of Business and Management, Donghua University, Shanghai, 200051, China \\ *E-mail:Shephard01@163.com
}

Keywords: Enterprises, Government, Consumers, Green Technology Innovation.

\begin{abstract}
As environmental pollution problem becomes increasingly serious, the driving force of green technological innovation from the government and public consumers is currently strengthening. Hence relationship of mutual restraint and interaction exists among the government, innovative enterprises, and general consumers are quite concerned. This paper proposes the tripartite evolutionary game model of the government, enterprises, and public consumers, then applies dynamic game evolution theory to build the third-party game payoff matrix, analyses the influences of enterprises, governments and consumers decision on green technology innovation through evolution model, the results show that pollution resistance measures of consumers will promote the diffusion of green technology innovation to some extent, high pollution regulation of governments make contributions to the green technology innovation as well.
\end{abstract}

\section{Introduction}

With Green wave of the global economy, a growing number of Enterprises realized that green technology innovation is not only to protect the environment but also the social responsibility of Enterprises. To gain a competitive advantage in the market, most of the Enterprises have to achieve the dual goals of economic performance and environmental performance. For macro ecological governance, to coordinate the contradiction between economic development and ecological environment, the Government actively supports the green management enterprises, such as provide financial subsidies and support policies for developing green products. Majority research shows that the green management behavior of Enterprises is influenced by government, policy, market, cost, law, consumer, etc. ${ }^{[1]}$, According to the institutionalism theory ${ }^{[2]}$, the organization is embedded in the institution environment, and the organization can obtain the legitimacy of social by isomorphism of institutional environment.

However, most Enterprises show negative attitude to the high barriers of green technology innovation and the cost of $\mathrm{RD}^{[3]}$, additionally, low public awareness of green technology innovation reduces the development and diffusion efficiency of enterprises green technology innovation ${ }^{[4]}$. Therefore, how to eliminate the old RD technology and promote the enterprise to carry on the green technology innovation under the public participation and the government environmental regulation is of great practical significance. 


\section{Literature review}

At present, the research on the driver force of green innovation mostly takes strategic management theory as the theoretical framework, and probes into the motivation and influence of enterprise's implementing environment strategy from the perspective of resource-based theory. Zhong Liu believes that under the influence of institutional environment, the institutional driving force of enterprise green technology innovation consists of regulatory, normative and cognitive pressures ${ }^{[5]}$. Zhang Haijiao stress green management must integrate by the whole process of production and management and adhere to the competitive green management strategy to establish the green competitive advantage of enterprises ${ }^{[6]}$. Zhu Qinghua suggests the external institutional pressure is the reason that the enterprise carries on the internal green practice, the enterprise's green supply chain practice also enhances the enterprise's economic performance and the operation performance indirectly ${ }^{[7]}$.

However, the heterogeneity of green innovation in industry shows that when the institutional pressure restraints of the enterprise's relatively strong, the enterprise's strategic response either chooses the breakthrough or passively subject to it, therefore the Enterprise green technology innovation practice heterogeneity is the result of triple institutional pressure synergy. From the previous literature, Kammerer points out Consumer environmental awareness, and government regulation can promote the application and technological innovation of environmental products ${ }^{[8]}$, Wang Bingcheng suggests that direct factors as such market demand and national legislation promote technology innovation and diffusion of green products, indirect factors including consumer income and product intellectual property rights ${ }^{[9]}$. Pujari discusses the role of market demand, technology, product life cycle and their coordination relationship in green product innovation activities through hierarchical regression method ${ }^{[10]}$. Cantonos proposes a green product diffusion network model based on the heterogeneity of consumers preference ${ }^{[11]}$.

On the whole, the existing research only focuses on the interaction between the government, consumers and the enterprises, and ignores the influence of the three parties combination driving force on green technology innovation. In fact, The enterprise embedded in a complex institutional environment is the connection point of the multi-stakeholder relationship, its green technology innovation strategy is influenced by the government and consumers, and the interaction of three parties will cause the change of the green technology innovation behavior of the enterprise. Based on this, this research applies institutional theory to construct the three-party evolutionary game model of government, enterprise, and public consumers, and analyze the influence of the evolution behavior of the three in different stages on the Green technology innovation strategy.

\section{Dynamic Game of Enterprise Green Technology Innovation}

(1) Green Technology Innovation Game Model Conditions

Given the strong regulatory pressure of the Chinese government, and the complexity of the technology on green innovation and the long-term return on investment, in order to realize the dynamic equilibrium between the enterprise and the government, we assumed that the government should try to provide the enterprise with the policy support especially for the small and medium-sized enterprises, and the consumers should stimulate the enterprises to carry out green innovation by actively buying green products. Condition 1, the government, enterprise and consumer for Enterprise technology green innovation consists of tripartite game, the government's regulation means includes publicizes the social environmental protection consciousness, the green innovation subsidy, the pollutant emissions right transaction, its execution strength factor is $\alpha, \beta, \gamma$, its corresponding regulation cost respectively is $\alpha I, \beta J, \gamma K$. 
Condition 2, Enterprises, consumers and government have two options, enterprises can choose whether to implement green innovation, the government can choose whether to conduct environmental regulation, consumers can choose whether to buy green products, $x, y, z$ indicate the probability of positive attitude of three parties, the probabilities are all the function of the period $t$, and belongs to $[0,1]$.

Condition 3, the profitability of before starting green technology innovation is set to $P$, the income of the enterprise is $\Delta P$ after the green innovation, and the green technology innovation income is $\Delta P_{1}$ when the government regulates and the consumers purchase green products. The enterprise green innovation income for $\Delta P_{2}$ when government does not regulate but consumers buy green products, the enterprise green Innovation income for $\Delta P_{3}$ when government regulation but consumers do not have green product purchasing power, the enterprise Green Innovation income is 0 if the government does not regulate and consumers do not have green product purchasing power, The investment cost of green technology innovation is $\mathrm{Ci}$, the government's environmental regulation income and loss are $P g$, $S g$, consumers buy green products creates environmental benefits is $P c$, and losses for $S c$ if consumers don't buy it, consumer's resistance to enterprise pollution is $\mathrm{Rm}$.

(2) Green Technology Innovation Game Model Evolution

After enterprises adopt green innovation, there will be two kinds of situations in the market, The number of enterprises that don't carry on green technology innovation set to $T_{0}$, and the number of enterprises that adopt green innovation in the market set to $T_{N}$,

$R_{1}$ and $R_{2}$ represent the Government's support strength for green technology innovation and the restrain strength for non-green innovation enterprise technology respectively. $\sigma_{n 0}=K_{n} / K_{0}$ indicates the barrier factor of backward technology to green innovation, it explains the purchasing power of consumers for non-green products, $\sigma_{0 n}=K_{0} / K_{n}$ indicates the renewal coefficient of green innovation to backward technology, it means the market purchase power of green products. Thus, we get the enterprises evolution state since they adopt green innovation in the period, it as follows:

$$
\left\{\begin{array}{l}
\frac{d T_{\mathrm{n}}(t)}{d t}=\mathrm{r}_{1} \mathrm{~T}_{\mathrm{n}}\left(1-\frac{\mathrm{T}_{\mathrm{n}}}{\mathrm{K}_{\mathrm{n}}}-\sigma_{\mathrm{n} 0} \frac{\mathrm{T}_{0}}{K_{n}}\right) \\
\frac{d T_{0}(t)}{d t}=\mathrm{r}_{2} \mathrm{~T}_{0}\left(1-\frac{\mathrm{T}_{0}}{\mathrm{~K}_{0}}-\sigma_{0 \mathrm{n}} \frac{\mathrm{T}_{\mathrm{n}}}{K_{0}}\right)
\end{array}\right.
$$

Under the different game strategies conditions, the three-party game matrix of enterprises, consumers, and governments as follows:

Table1 Trilateral Game Matrix of Consumer Boycott and Government Regulation

\begin{tabular}{l|c|c|c}
\hline & \multicolumn{3}{|c}{ Government adopt environmental regulation } \\
\cline { 2 - 4 } & $\begin{array}{c}\text { Enterprise } \\
\text { Payment function }\end{array}$ & $\begin{array}{c}\text { Government } \\
\text { Payment function }\end{array}$ & $\begin{array}{c}\text { Consumer Payment } \\
\text { function }\end{array}$ \\
\hline $\begin{array}{l}\text { After adoption of green } \\
\text { technology innovation }\end{array}$ & $P+\Delta P_{2}-C_{l}$ & $P_{g}-a I-\beta J$ & $P_{c}-R_{M I}$ \\
\hline $\begin{array}{l}\text { before the adoption of } \\
\text { green technology } \\
\text { innovation }\end{array}$ & $P$ & $\gamma K-a I-S_{g}$ & $-R_{m I}-S_{c}$ \\
\hline
\end{tabular}


Table 2 Trilateral Game Matrix of Consumer Boycott but without Government Regulation

\begin{tabular}{l|c|c|c}
\hline & \multicolumn{3}{|c}{ Government do not adopt environmental regulation } \\
\cline { 2 - 4 } & $\begin{array}{c}\text { Enterprise } \\
\text { Payment function }\end{array}$ & $\begin{array}{c}\text { Government } \\
\text { Payment function }\end{array}$ & $\begin{array}{c}\text { Consumer Payment } \\
\text { function }\end{array}$ \\
\hline $\begin{array}{l}\text { After adoption of green } \\
\text { technology innovation }\end{array}$ & $P+\Delta P_{1}+\beta j-C$ & $P_{g}$ & $P_{c}-R_{M 2}$ \\
\hline $\begin{array}{l}\text { before the adoption of } \\
\text { green technology } \\
\text { innovation }\end{array}$ & $P-\gamma K$ & $-S_{g}$ & $-S_{c}-R_{m 2}$ \\
\hline
\end{tabular}

Table 3 Trilateral Game Matrix of Regulation but without Consumer Boycott

\begin{tabular}{l|c|c|c}
\hline & \multicolumn{2}{|c}{ Government adopt environmental regulation } \\
\cline { 2 - 4 } & $\begin{array}{c}\text { Enterprise } \\
\text { Payment function }\end{array}$ & $\begin{array}{c}\text { Government } \\
\text { Payment function }\end{array}$ & $\begin{array}{c}\text { Consumer Payment } \\
\text { function }\end{array}$ \\
\hline $\begin{array}{l}\text { After adoption of green } \\
\text { technology innovation }\end{array}$ & $P+\Delta P_{3}-C_{l}$ & $P_{g}-a I-\beta J$ & $P_{c}$ \\
\hline $\begin{array}{l}\text { before the adoption of } \\
\text { green technology } \\
\text { innovation }\end{array}$ & $P-\gamma K$ & $\gamma K-a I-S_{g}$ & $-S_{c}$ \\
\hline
\end{tabular}

Table 4 Trilateral Game Matrix of without Regulation and Consumer Boycott

\begin{tabular}{l|c|c|c}
\hline & \multicolumn{3}{|c}{ Government do not adopt environmental regulation } \\
\cline { 2 - 4 } & $\begin{array}{c}\text { Enterprise } \\
\text { Payment function }\end{array}$ & $\begin{array}{c}\text { Government } \\
\text { Payment function }\end{array}$ & $\begin{array}{c}\text { Consumer Payment } \\
\text { function }\end{array}$ \\
\hline $\begin{array}{l}\text { After adoption of green } \\
\text { technology innovation }\end{array}$ & $P-C_{l}$ & $P_{g}$ & $P_{c}$ \\
\hline $\begin{array}{l}\text { before the adoption of } \\
\text { green technology } \\
\text { innovation }\end{array}$ & $P$ & $-S_{g}$ & $-S_{c}$ \\
\hline
\end{tabular}

With the development and progress of technology, the game of green technology innovation of enterprises will evolve with the time before they reach the equilibrium state, because of the information asymmetry between the game parties, the strategy decision of either party can only be based on its own experience and the strategy of other parties. According to the probability of three strategy alteration $x, y, z$, From the above tables, we get the Replicator dynamics equations of enterprises, government, and consumers as follows,

$$
\begin{gathered}
U_{1}(x)=d x / d t=\left(E_{11}-E_{1}\right) x=x(1-x)\left[\left(\Delta P_{1}-\Delta P_{2}-\Delta P_{3}\right) y z+\Delta P_{2 z}+\Delta P_{3 y}+C_{1 y}+C_{1}+\gamma K_{y}\right] \\
U_{2}(y)=d y / d t=\left(E_{21}-E_{2}\right) y=y(1-y)\left(S_{g} x-\gamma K x-\beta J x+S_{g}+\gamma K+\alpha I\right) \\
U_{3}(z)=d z / d t=\left(E_{31}-E_{3}\right) z=z(1-z)\left(R_{m 2} y-R_{m 1} y-R_{m 2}\right)
\end{gathered}
$$

After the continuous cooperation and confrontation, the final three-party Nash equilibrium obtained. In order to seek the tripartite equilibrium point under the condition of government regulation, we assume $U_{1}(x)=0, U_{2}(y)=0, U_{3}(z)=0$, then we get 8 special equilibrium points, i.e. $(1,1,0),(0,1,1)$, $(1,0,1),(0,1,0),(0,0,1),(1,1,1),(0,0,0),(1,0,0)$.

When $U^{\prime}{ }_{1}(x)<0, U_{2}(y)<0, U_{3}^{\prime}(z)<0, U_{1}(x), U_{2}(y), U_{3}(z)$, the tripartite equilibrium of the 
three-party game strategy is achieved, $U_{1}(x)=0, U_{2}(y)=0, U_{3}(z)=0$ means the evolutionarily stable strategy of three-party adopt, as shown in the following,

$$
\begin{array}{r}
U_{1}^{\prime}(x)=(1-2 x)\left[\left(\Delta P_{1-}-\Delta P_{2}-\Delta P_{3}\right) \mathrm{yz}+\Delta P_{2} z+\Delta P_{3} y+C_{1} y+\gamma K_{y}\right] \\
U^{\prime}{ }_{2}(y)=(1-2 y)\left(S_{g} x-\gamma K_{x}-\beta J x+S_{g}+\gamma K-a I\right) \\
U^{\prime}{ }_{3}(z)=(1-2 z)\left(R_{m 2} y-R_{m 1} y-R_{m 2}\right)
\end{array}
$$

It is shown that the game evolution of the enterprise depends on quadratic curve $\left(\Delta P_{1}-\Delta P_{2}-\Delta P_{3}\right) \mathrm{yz}+\Delta P_{2} z+\Delta P_{3} y+C_{1} y+\gamma K_{y}=0$,

The game evolution of government depends on curve $S_{g} x-\gamma K_{x}-\beta J x+S_{g}+\gamma K-a I=0$.

The game evolution of consumer game depends on linear equations $R_{m 2} y-R_{m 1} y-R_{m 2}=0$.

To fully demonstrate the equilibrium state model of the diffusion of green technology innovation in the market, we assume $\frac{d T_{\mathrm{n}}}{d t}=\frac{d T_{0}}{\mathrm{~d} t}$, then we obtain as following,

$$
\left\{\begin{array}{l}
\frac{\mathrm{d} T_{n}(t)}{d t}=\mathrm{r}_{1} \mathrm{~T}_{\mathrm{n}}\left(1-\frac{T_{n}}{K_{n}}-\sigma_{n 0} \frac{T_{0}}{K_{n}}\right)=0 \\
\frac{\mathrm{dT}_{0}(\mathrm{t})}{\mathrm{dt}}=\mathrm{r}_{2} \mathrm{~T}_{0}\left(1-\frac{\mathrm{T}_{0}}{\mathrm{~K}_{0}}-\sigma_{0 \mathrm{n}} \frac{\mathrm{T}_{\mathrm{n}}}{\mathrm{K}_{0}}\right)=0
\end{array}\right.
$$

At this point, we can see four-game equilibrium points in the model, namely $\mathrm{A}(0,0) 、 \mathrm{~B}\left(0, \mathrm{~K}_{0}\right)$ 、 $\mathrm{C}(\mathrm{Kn}, 0) 、 \mathrm{D}\left[\frac{K_{\mathrm{n}}\left(1-\sigma_{n 0}\right)}{1-\sigma_{n 0} \sigma_{0 n}}, \frac{K_{0}\left(1-\sigma_{n 0}\right)}{1-\sigma_{n 0} \sigma_{0 \mathrm{n}}}\right]$. Point $\mathrm{D}$ is the Nash equilibrium solution to be explored in this paper.

When the enterprise's green technology innovation product market share is low, the previous backward technology will restrain the enterprise to adopt the new environmental protection technology, when the green technology innovation gradually diffuses along with the green product market demand level enhancement, the whole game system finally reach the equilibrium state. We assume the linear P and linear Q as following,

$$
\left\{\begin{array}{l}
P\left(T_{n}, T_{0}\right)=1-\frac{\mathrm{T}_{\mathrm{n}}}{\mathrm{K}_{\mathrm{n}}}-\sigma_{\mathrm{n} 0} \frac{T_{0}}{K_{\mathrm{n}}}=0 \\
Q\left(T_{n}, T_{0}\right)=1-\frac{\mathrm{T}_{0}}{\mathrm{~K}_{0}}-\sigma_{n 0} \frac{T_{n}}{K_{0}}=0
\end{array}\right.
$$

With continual learning experience and practice of game parties, as long as governments impose regulations on and consumers resists companies that produce non-green products, the number of companies that had previously used backward technology would fall down, then the number of green innovation manufactures grow, as shown in Figure 1 below, the game parties out of line $\mathrm{P}$ and Line Q gradually approach to the aggregation around two lines, the final evolution of the game will end with the green products occupy the market. 


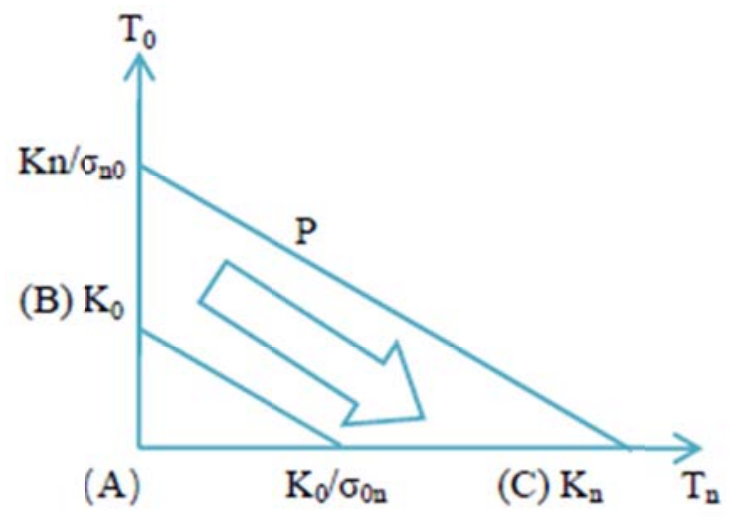

Fig. 1 Equilibrium Solution 1 of Trilateral Game

However, in the above process, if the game cost between government and consumers pay too high, since the government and consumers cancel the regulation and resist on the non-environmental manufacturers, it may lead to the slowly diffusion period of green technology innovation, Manufacturers with backward technology are likely to make a comeback, it may stop the spread of green technology innovation in market. As shown in Figure 2 below,

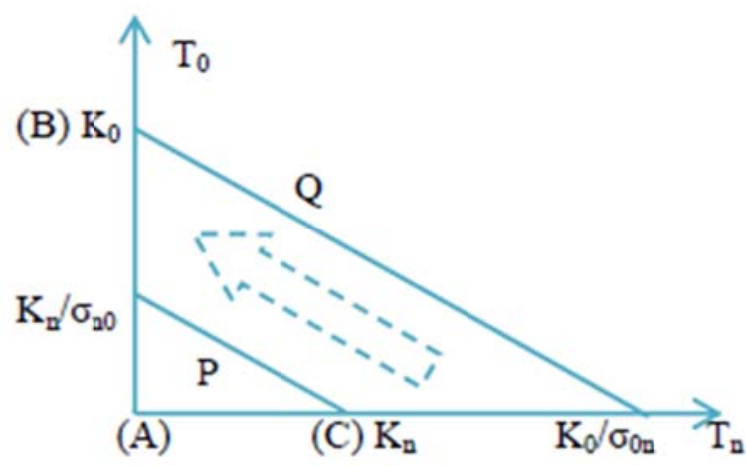

Fig. 2 Equilibrium Solution 2 of Trilateral Game

These two equilibrium solutions illustrate the attitude and decision of different enterprises towards green technology innovation, the enterprises with different scale and technology capabilities compete with each other by their advantages. At the same time, if consumers and the government start to oppose the non-green manufacturers, then green manufacturers will compete with the non-green manufacturers in market again, green technology innovation products and non-green products diffuse in the same period, that is a confrontation between green and non-green manufacturers, and they final achieve dynamic coexistence in the market. As shown in Figure 3 and Figure 4 below.

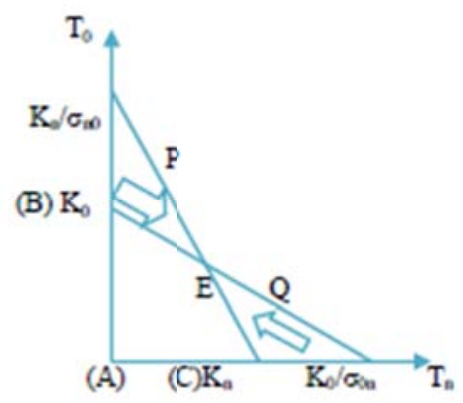

Fig. 3 Equilibrium Solution 3 Fig. 4 Equilibrium Solution 4

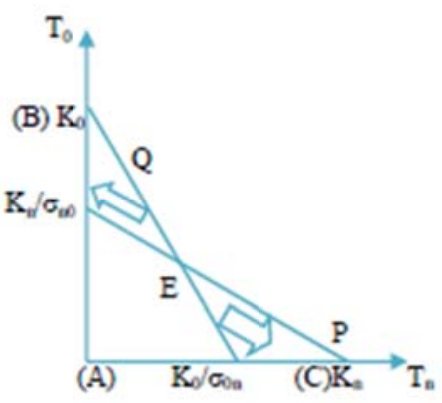


From the above-mentioned game equilibrium solution 3 and solution 4, we can learn that, In the evolution of the 3 parties game of government, consumer, and enterprises, three results can be derived in the end, namely green technology innovation product will spread to the entire market, green technology innovation product coexist with non-green products, and non-green producers dominate the markets.

\section{Conclusions}

This paper applies dynamic game evolution theory to build the third-party game payoff matrix, analyses the influences of enterprises, governments and consumers decision on green technology innovation through evolution model, the results show that pollution resistance measures of consumers will promote the diffusion of green technology innovation to some extent, high pollution regulation of governments make contributions to the green technology innovation as well.

We conclude following aspects, firstly, the government should choose reasonable environmental regulatory measures to lower the cost of environmental regulation. Secondly, consumers have an extensive and intensive influence to play for the promotion of green technological innovation; they should stop consuming non-green products to continuously push forward the development of green innovation technologies. Thirdly, enterprises should make every efforts to research and develop green technology products to reduce environmental pollution and consumption of energy.

\section{References}

[1] Klassen R. D., Mclaughlin C. P..The Impact of Environmental Management on Firm Performance. Management Science,1996, 42(8): 1199-1214.

[2] DiMaggio,P.J, Powell,W.W. The Iron Cage Revisited: Institutional Isomorphism and Collective Rationality in Organizational Fields [J]. American Sociological Review,1983,48(2):147-160.

[3] Deng Feng. Game between the Government and Enterprise Under Incompletely Implemented Regulations of Pollution [J]. Forecasting, 2013, 32( 1): 67-71.

[4] Li Ping. Study on the Subject System of Green Technology Innovation[J]. Studies in Science of Science, 2015,33(3) : 414-418.

[5] Zhong Liu. Study on Institutional Drivers of Green Management Model and Innovation Path[J]. Science \& Technology Progress and Policy,2014,31(12):12-17.

[6] Zhang Haijiao, Cao Fang. Construction of Competitive Green Management Strategy: Based on Empirical Research on Management and Competitive Advantage[J]. Science \& Technology Progress and Policy,2013, 30(9): 96-100.

[7] Qinghua Zhu, Joseph Sarkis. Institutional-based antecedents and performance outcomes of internal and external green supply chain management practices[J]. Purchasing and Supply Management. 2013,19(2): 106-117.

[8] Kammerer D. The effects of customer benefit and regulation on environmental product innovation: Empirical evidence from appliance manufactures in Germany[J]. Ecological Economics, 2009, 68(8):2285-2295.

[9] Wang Bingcheng, Li Hongwei. Empirical research on the impact factors of green product innovation by structural equation modeling[J]. China Population Resources and Environment, 2009, 19(5): 168-174.

[10] Pujari D. Eco-innovation and new product development: Understanding the influences on market performance[J]. Technovation,2006, 26(1):76-85.

[11] Cantono S, Silverberg G. A percolation model of eco-innovation diffusion: The relationship between diffusion, learning economies and subsidies[J]. Technological Forecasting and Social Change, 2009, 76(4):487-496. 